\title{
INTERIORIDAD HABITADA. IPSEIDAD Y ALTERIDAD EN LAS 'MORADAS' DE SANTA TERESA DE JESÚS ${ }^{1}$
}

\author{
INHABITED INTERIORITY. IPSEITY AND ALTERITY IN THE \\ 'MORADAS' BY SAINT TERESA OF JESUS
}

\author{
GABRIEL AMENGUAL COLL \\ Universitat de les Illes Balears-IEHM
}

Recibido: $12 / 05 / 2020 \quad$ Aceptado: $23 / 09 / 2020$

\section{RESUMEN}

Expone la concepción teresiana de la subjetividad, atendiendo especialmente a Moradas del castillo interior. Se muestra que el sujeto se caracteriza tanto por su dimensión temporal (se encuentra siempre en proceso de hacerse) y la dimensión relacional (se hace por medio de las relaciones). Se da mucha importancia al autoconocimiento, que se da en el encuentro con el otro; la ipseidad se forma por el encuentro con la alteridad. La concepción teresiana de la subjetividad apunta a una unidad entre ipseidad y alteridad.

Palabras clave: Alteridad, autoconocimiento, interioridad y exterioridad, ipseidad, socratismo teresiano.

1 Este trabajo ha sido realizado con la ayuda del Centro Español de Estudios Eclesiásticos anejo a la Iglesia Nacional Española de Santiago y Montserrat en Roma en el marco de los proyectos de investigación del año 2020. 


\section{ABSTRACT}

It exposes the Teresian conception of subjectivity, paying special attention to $\mathrm{Mo}$ radas del castillo interior. It is shown that the subject is characterized both by its temporal dimension (it is always in the process of being made) and the relational dimension (it is made through internal relationships). Much importance is given to self-knowledge, which occurs in the encounter with the other; ipseity is formed by the encounter with otherness. The Teresian conception of subjectivity points to a unity between ipseity and otherness.

Keywords: Alterity, self-knowledge, interiority and exteriority, selfhood, Teresian Socratism.

Se trata de una exposición de la concepción teresiana de la subjetividad. Se hace desde el trasfondo de la crítica contemporánea del sujeto que reprocha que sea pensado más bien como sustancia fija, un punto fijo de imputación de capacidades y acciones, carente de dimensión temporal (que se encuentra siempre en proceso de hacerse) y de la relacional (que se hace por medio de las relaciones, no es algo cerrado en sí). Esta misma crítica puede servirnos de guía para rastrear cómo lo entiende la escritora abulense. Vamos a estudiar esta concepción del sujeto, tal como se desprende de sus escritos, con especial atención a Moradas del castillo interior (1577). Este estudio sigue la línea de otros sobre Santa Teresa de Jesús ${ }^{2}$ y la concepción ignaciana de sujeto ${ }^{3}$.

\section{TERMINOLOGÍA Y CONTEXTO CULTURAL}

Curiosamente el término interioridad no figura en el vocabulario teresiano, aunque sí con abundancia los de interior, interiormente, así como también bajo términos equivalentes como adentro, centro, dentro, entrañas, hondo, íntimo, profundo, tuétano, como también alma, corazón, etc. y con expresiones como "lo interior del alma" o "lo interior del hombre" (7M2,2.6), "el centro muy

2 Gabriel Amengual, Afines por elección. En torno a los inicios de la modernidad en España (Madrid: Sindéresis 2018), 71-102 y 103-114.

3 Gabriel Amengual, "La concepción ignaciana del sujeto", Argumenta Philosophica (2021), en prensa.

4 Santa Teresa de Jesús, Obras completas, ed. por Efrén de la Madre de Dios y Otger Steggink, 9 ed. (Madrid: BAC, 2002). Las obras se citan según esta edición y con las siglas usuales. En caso de 
interior del alma" (7M2,3), "puro espíritu" (7M2,7), "lo muy muy interior" (7M1,7), "lo profundo de nosotros", "el hondón interior" $(4 \mathrm{M} 2,6)$. También el término sujeto es usado por la santa (17 veces) aunque con un significado que no es todavía de manera clara el moderno; lo usa en el sentido de el natural, la condición humana, naturaleza, y ya más cercano al moderno como alma, persona ${ }^{5}$.

El contexto cultural viene dado por la llamada espiritualidad o mística del recogimiento, de la que brota la mística española del siglo XVI y que inspiró a la Santa, aunque ésta ofrezca una concepción propia. Entre los rasgos de la mística del recogimiento destaca "la valoración de la experiencia personal ${ }^{6 “ " ~(A n-~}$ drés Martín 1984, 9). El realismo de la mística se manifiesta en la oración de propio conocimiento, que es su punto de partida, realizando una aportación importante a la técnica del análisis interior y de la experiencia vivencial. De modo que también encarnan una de las manifestaciones más preclaras de la modernidad, a saber, la exposición de la experiencia personal y la autobiografía.

Los rasgos mencionados confluyen en el de interioridad, entendida como "la vuelta del hombre hacia sí mismo en busca de Dios, más íntimo a él que su misma intimidad; en entrarse el hombre en el centro o fondo de su alma; la su-

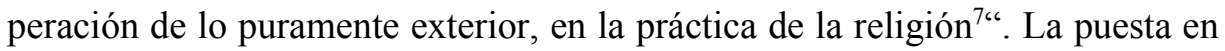
valor de la interioridad no lleva a los místicos a un interiorismo a ultranza con su consiguiente dualismo. Frente al dualismo se observa en los místicos una integración de la persona humana en unidad de acción o de naturaleza. Sus bases antropológicas deben más a la psicología aristotélica que a la platónica, de modo que unen razón y sensibilidad, sentidos y potencias del alma, cuerpo y alma, lo carnal y lo espiritual, interno y externo ${ }^{8}$.

A partir de estas simples pinceladas podemos preguntarnos cómo entiende Teresa esta interioridad y el proceso que significa.

no haber sigla clara de algún escrito menor, se indicará simplemente el número de página (p.) en el texto.

5 Juan Luis Astigarraga y Agustí Borrell, eds., Concordancias de los escritos de Santa Teresa de Jesús (Roma: OCD, 2000), 2 vols.

6 Melquíades Andrés Martín, "Procesos de interioridad en la mística española (1500-1535). La reflexión de las potencias al centro del alma, como método dialéctico para la contemplación quieta". En Santa Teresa y la literatura mistica hispánica, dir. Manuel Criado de Val (Madrid: Edi-6, 1984), 9.

7 Andrés Martín, "Procesos de interioridad", 10s.

8 Andrés Martín, "Procesos de interioridad", 13. 


\section{EL CASTILLO O LA INTERIORIDAD}

\section{EL ALMA: IPSEIDAD Y ENCUENTRO}

El punto de partida es la inicial afirmación: "considerar nuestra alma como un castillo" $(1 \mathrm{M} 1,1)$. El castillo es por tanto todo ser humano, y más en concreto su alma o interioridad, su subjetividad. Su primera característica es la belleza y gran valor: "un castillo todo de un diamante o muy claro cristal"; "no es otra cosa el alma del justo, sino un paraíso", ofreciendo una gran variedad de estancias, "aposentos" (1M1,1). "La hermosura de este castillo" no es sino manifestación de "la gran dignidad y hermosura del ánima", que está hecha por Dios "a su imagen" (1M 1,1). De entrada, pues, la primera mirada al castillo, desde el exterior y su materialidad, mostrando su belleza, remite a otro, a Dios.

No todas las moradas tienen la misma calidad; en "el centro y mitad de todas éstas la más principal, que es adonde pasan las cosas de mucho secreto entre Dios y el alma" (1M1,3). "El centro, que es la pieza u palacio a donde está el rey" $(1 \mathrm{M} 2,8)$, ahí es donde hay que poner los ojos y a donde lleva todo el itinerario. No sólo el material del que está hecho el castillo remite a Dios, sino también su función; el castillo ya no es sólo el alma, sino el lugar de encuentro entre Dios y el alma. De modo que la cuestión primera es "cómo podremos entrar en él" (1M1,5). La Santa se da cuenta de la paradoja o aparente contradicción entre ser nosotros mismos este castillo y tener que entrar en él. "Parece que digo algún disparate; porque si este castillo es el ánima, claro está que no hay para qué entrar, pues se es él mismo". Su respuesta es clara: "Mas habéis de entender que va mucho de estar a estar", pues el castillo no sólo tiene muchos aposentos, sino también un foso y un entorno, con animales y gente alrededor y por tanto uno puede estar "en la ronda del castillo" sin saber "qué hay en aquel tan precioso lugar ni quién está dentro ni aun qué piezas tiene" $(1 \mathrm{M} 1,5)$. Uno puede vivir fuera de sí, distraído o disperso, sin saber de qué va su vida ni qué se juega en ella.

El castillo como lugar de encuentro exige además no ser fuera de sí, sino ser uno mismo. Es la afirmación de uno mismo que es a la vez la propuesta de una tarea, llegar a ser uno mismo, eligiendo ser uno mismo, dejando de ser el "uno" impersonal o un número dentro de una masa informe y anónima que no tiene más opinión o afecto o deseo que lo que se opina, se siente, se desea, porque se mueve al dictado de corrientes de opinión o de pensamiento o al azar del humor del momento. Así se podrían traducir a la vida real las metáforas de las "savandijas y bestias" $(1 \mathrm{M} 1,6)$ que rondan el castillo en el lenguaje de Teresa. El primer paso es, por tanto, entrar dentro de sí, ser uno mismo, para ir al encuentro del otro. Ipseidad es para el encuentro con la Alteridad. Es el primer 
paso, porque efectivamente el hombre puede vaciarse y derramarse fuera de sí, vivir una vida dispersa y fragmentada, desentendiéndose de sí mismo, lo cual "sería gran bestialidad" (1M1,2), significaría reducir el hombre a la condición de las "alimañas"; "caer en semejante bestialidad", la pérdida de la interioridad, afecta, pues, al ser hombre (1M1,7). Un tema agustiniano que recuerda la afirmación "Vos estabais en mi, y yo fuera de mi" (Conf X,27,38). Dios es "más interior en mí que mi fondo más íntimo, y más alto que la cima más alta de mí" (Conf III,6,11).

\section{EL SOCRATISMO TERESIANO}

"No es pequeña lástima y confusión que por nuestra culpa no entendamos a nosotros mismos ni sepamos quién somos" $(1 \mathrm{M} 1,2)$. Desde el inicio se pone ya en juego el llamado "socratismo teresiano", la necesidad de conocerse a sí mismo. Un tema agustiniano muy presente en la santa abulense, pero también muy moderno y contemporáneo, que reviste formas diversas: la necesidad de superar la vida alienada para poder ser uno mismo (Marx), o elegir ser sí mismo (Kierkegaard), o convertirse para alcanzar la vida justa y feliz (Foucault). Teresa dirá que "la puerta para entrar en este castillo es la oración y consideración" $(1 \mathrm{M} 1,7)$. Seguramente en el acto de la oración entran todos estos aspectos: entrada en uno mismo, búsqueda de la verdad, deseo del encuentro con Dios. Ella es la puerta, puesto que es la entrada, pero también va a estar presente en todo el itinerario, nada extraño si el castillo es lugar de encuentro y la oración es el encuentro en acto.

Quizás sin saberlo, el socratismo teresiano tiene mucho de socrático-platónico, por lo menos comparten dos características decisivas. "Conócete a ti mismo" es un mandato divino, esculpido en la entrada del templo de Delfos, como si indicara la condición para entrar en el templo. Dice referencia a Dios, puesto que en el templo, en la relación con Dios, se va a cumplir el mandato. En segundo lugar, conocerse a sí mismo implica conocer los propios límites, de tal modo que solamente es sabio aquel que sabe de sus límites. Este aspecto Teresa lo tematizará como humildad, Sócrates-Platón en la figura del sabio, que es aquel que sabe que no lo sabe todo o que sabe que no sabe nada. A Teresa le llegaría por el eco de S. Agustín: noverim me, noverim te (Soliloquios II,1): autoconocimiento para alcanzar el conocimiento de Dios.

Para el itinerario hacia el centro importa mucho el conocerse a sí mismo. He ahí una característica del socratismo teresiano: "jamás nos acabamos de conocer, si no procuramos conocer a Dios" (1M2,9; 1M2,13). ¿Por qué esta referencia a Dios en el proceso del autoconocimiento? Primeramente porque el 
referente para la propia definición del ser humano para Teresa no es, como en la antropología clásica, la diferencia con el animal, sino la relación con Dios. El contraste entre Dios y el hombre hace resaltar más lo propio de cada uno: "está claro que parece una cosa blanca muy más blanca cabe la negra, y al contrario la negra cabe la blanca" $(1 \mathrm{M} 2,10)$. Pero en el autoconocimiento no sólo opera la vía del contraste, sino que precisamente ante Dios aparecemos tal como somos, pues ante él no valen subterfugios ni apariencias, él ve lo más recóndito de nosotros mismos, llenándolo de luz; ante Él aparece "la gran hermosura del alma" (1M1,1); ante Él tampoco se detiene uno en conceptos universales, sino que cada uno aparece con lo más propio y peculiar; se trata pues de conocernos a la luz de Dios, que nos conoce más y mejor que nosotros mismos y además nos ama ${ }^{9}$ por ello "nuestro entendimiento y voluntad se hace más noble y más aparejado para todo bien tratando a vueltas de sí con Dios; y si nunca salimos de nuestro cieno de miserias, es mucho inconveniente" $(1 \mathrm{M} 2,10)$. Dios, el otro, entran en el proceso del autoconocimiento, de modo que éste se consigue por mediación del otro. La ipseidad se forma mediante la alteridad.

El autoconocimiento importa especialmente porque conduce a la humildad: "mientras estamos en esta tierra no hay cosa que nos importe más que la humildad" $(1 \mathrm{M} 2,9)$. Pero una humildad que nada tiene que ver con actitudes menospreciadoras de sí mismo y de apocamiento, sino que consiste en "andar en la verdad", como repetidamente dice la Santa. Entonces, ¿en qué consiste andar en la verdad?: "No digo sólo que no digamos mentira [...]; sino que andemos en verdad delante de Dios y de las gentes de cuantas maneras pudiéremos, en especial no queriendo nos tengan por mejores de lo que somos, y en nuestras obras dando a Dios lo que es suyo y a nosotras lo que es nuestro, y procurando sacar en todo la verdad, y así tendremos en poco este mundo, que es todo mentira y falsedad, y como tal no es durable" (6M10,7). Andar en verdad significa, pues, profesar la verdad no sólo de palabra, sino sobre todo en hechos de vida, que nuestra existencia sea auténtica y según verdad, sin ficciones o falseamientos; conocer y reconocer los propios valores, sabiendo que los hemos recibido, y conocer también nuestros contravalores, nuestra miseria, sabiendo que -como dice el salmo (Ps 115,11) y Teresa cita- "todo hombre es mentiroso" (6M10,6), es decir, que tendemos a justificarnos y por ello a camuflar la realidad o fingir realidades paralelas, otros relatos, metidos en un mundo de mentira y apariencia. Conocernos como somos conocidos por Dios, ante el cual somos transparentes, libera de todas estas farsas.

9 Tomás Álvarez, Comentarios a 'Vida', 'Camino' y 'Moradas' de Santa Teresa (Burgos: Monte Carmelo, 2005), 564-566, 750-752. 


\section{EL CASTILLO COMO ITINERARIO: RECOGIMIENTO Y ENCUENTRO}

La paradoja de tener que entrar en uno mismo se dobla en que para entrar en sí mismo hay que salir de sí. El itinerario hacia el centro, que es lo más íntimo de uno mismo, exige salir de sí mismo, abrirse al otro. La interiorización o recogimiento para Teresa consiste en esta peregrinación hasta lo más hondo de uno mismo, que es a la vez salida de sí para encontrarse con la alteridad absoluta, Dios, que, por muy otro que sea, no es extraño, sino que es lo más íntimo de nosotros mismos. Hay que salir de sí mismo y poner los ojos en Cristo (1M2,11), que es el hondón y el centro.

Esta peregrinación misma hacia el centro presenta también su paradoja. Por una parte, no es rectilínea, tiene sus vueltas y revueltas, sus avances y retrocesos; las etapas no se dejan atrás de modo definitivo, sino que de alguna manera todas se dan en cada una, solo que en planos diferentes y con los elementos en intensidad diferente. "No habéis de entender estas moradas una en pos de otra, como cosa en hilada [hilera], sino poned los ojos en el centro, que es la pieza o palacio adonde está el rey" $(1 \mathrm{M} 2,8)$. Para ello sugiere otra metáfora, el palmito: "considerad como un palmito, que para llegar a lo que es de comer tiene muchas coberturas que todo lo sabroso cercan" $(1 \mathrm{M} 2,8)$. Aquí, en cambio, todo está de tal manera orientado hacia el centro que sugiere que las etapas anteriores son hojarasca. Esta metáfora del palmito recuerda la de la cebolla de Henrik Ibsen (Peer Gynt, 1867), pero con una conclusión contrapuesta: para Ibsen la cebolla (el ser humano) se va deshojando totalmente de modo que sólo quedan cortezas, deshechos, al final, nada; para Teresa, en cambio, el palmito se deshoja haciendo aparecer lo sabroso, el corazón, el hondón. En algo más coinciden, pues también para Teresa al final en cierta medida ha desaparecido o diluido el yo inicial, se ha transformado y unido al que le esperaba en el centro del castillo. La ipseidad, sin dejar de ser ella, se ha hecho una con la Alteridad. Como explica Ricoeur, el sí mismo, en tanto que ipseidad, está siempre ya habitado por una cierta alteridad. La alteridad "no se añade desde fuera a la ipseidad", sino que pertenece fundamentalmente "al tenor de sentido y a la constitución ontológica de la ipseidad ${ }^{10 ،}$.

El castillo presenta, pues, un itinerario hacia el centro, es un camino de interiorización o recogimiento y a la vez de encuentro con el Otro, aunque más íntimo que mí mismo.

10 Paul Ricoeur, Soi-même comme un autre (Paris: Seuil, 1990) y Gabriel Amengual, "P. Ricoeur: Del sujeto quebrado a la hermenéutica del sí', Anthologica Annua (2021, en prensa). 


\section{El CASTILLO, CAMPO DE BATALLA Y DE TENSIÓN}

La primera mirada del castillo destacaba la belleza; en su ser el hombre es bello; pero su historia está también plagada de inquietudes, de deseos y de mal. El realismo de Teresa no puede olvidarlo. En el recogimiento ya se aludía a la tarea de unificar, ordenar, armonizar las potencias del alma, lo cual significa que no todas por sí mismas están ya acordadas.

La llamada a la lucha, Santa Teresa la formula de esta manera: "Siempre esté con aviso de no se dejar vencer; [...] sino que se determine que va a pelear con todos los demonios y que no hay mejores armas que las de la cruz" (2M 6). ¿Contra qué o quiénes va la lucha? Aparecen como tres frentes: El frente interior viene dado por el desorden y conflicto entre las potencias del alma (2M9). El frente exterior está formado por los estímulos exteriores que, especialmente cuando tocan cuerdas interiores, pueden ser de fuerte impacto y de difícil combate, puesto que entonces pueden encontrar connivencia, comprensión y cooperación. En el frente trascendente aparecen otras fuerzas, diabólicas, que también están al acecho; los "demonios" dirá la Santa; se trata de aquellas fuerzas misteriosas que desbordan nuestro campo. La lucha no tiene otro fin que mantenerse fiel en las pruebas, que vienen dadas por las tentaciones y aquellas situaciones que nos ponen a prueba.

Otro aspecto de la lucha, la tensión y el conflicto lo ofrecen los deseos. También a Teresa cabría llamarla "mujer de deseos": "Deseos siempre los tuve grandes" (Vida 13,6). No se trata de deseos cualesquiera, sino de aquellos en los que va la vida (Vida 16,5). Su deseo último le entabla esta lucha a vida o muerte. Con la misma idea conecta la célebre sentencia "muero porque no muero".

Pero los deseos no se deciden solamente ante el final de la vida, sino en la vida en su totalidad, determinándola por entero, en la que el deseo cual imán le confiere una dirección y una energía. Teresa lo expresa con el símbolo de la herida, el corazón herido, aludiendo a pasajes bíblicos como los salmos (la cierva herida Ps 41,2,7M3,13) o el Cantar de los Cantares (vulnerasti cor meum, la herida del esposo Cant 5,8). La herida en este caso da a entender que no es algo pasajero, sino que queda marcado en la carne misma de modo permanente. "El alma ya queda herida del amor del Esposo" (6M1,1), con ello se da a entender que es el Esposo-Dios quien enciende los deseos, pues es él que "se lo hace desear" $(6 \mathrm{M} 2,1)$. Esta acción de Dios concuerda con lo más profundo de uno mismo; los deseos provocados por Dios, tienen una raíz profunda, "son unos impulsos tan delicados y sutiles, que proceden de lo muy interior del alma" $(6 \mathrm{M} 2,1)$ y tienen el efecto que así "su Majestad la despierta" y el alma se siente 
claramente "llamada de Dios" $(6 \mathrm{M} 2,2)^{11}$. Se hace difícil distinguir entre la acción de Dios y la del alma. El deseo ha sido colmado y a la vez engrandecido y por ello continúa siendo deseo, mayor deseo y por ello insaciable.

\section{INTERIORIDAD Y EXTERIORIDAD}

La interioridad no puede ser ajena a la exterioridad, la requiere para su constitución, formación y trayectoria. La interioridad, por mucho que viva en lo más profundo de su alma, vive en comunidad, en el mundo, en la historia, con el recuerdo de la propia historia, de "aquellos santos padres antiguos nuestros del Monte Carmelo" $(5 \mathrm{M} 1,2)$, en la sociedad y en el seno de la Iglesia, con la que sienten y viven a su ritmo; a su vez esta interioridad requiere expresarse, salir de sí y efectuar en el exterior lo que ella es en sí misma: unión, amor y por tanto acción.

Teresa manifiesta siempre un gran respeto por cada persona, sus capacidades y modos de ser y obrar; es más, respeta y promociona. En sus escritos, siempre tan exhortativos, no se cansa de decir que lo que ella expone es su experiencia que puede que no siempre coincida con la de los demás y que su modo de hacer es el suyo y que cada uno verá si le cuadra o como aplicárselo a su vida. Sin embargo, los otros tienen un papel decisivo en la formación del sujeto en su interioridad. Se trata siempre de un sujeto radicalmente relacional, que vive y obra en relación con otros: Dios, la Trinidad, Cristo, el Espíritu, la comunidad, la sociedad, amigas, la Iglesia, la priora, los confesores, los directores espirituales, los teólogos, la autoridad en general. ${ }^{12}$

En la toma de decisiones contó siempre con el aval del confesor, director espiritual o de algún teólogo, y en general de la autoridad de la Iglesia. Los otros entran a formar parte de las propias decisiones y en este sentido son elementos configuradores de la propia subjetividad y trayectoria vital e incluso de su propia identidad.

Así un criterio elemental es que "jamás haga nada ni le pase por pensamiento sin parecer de confesor letrado y avisado y siervo de Dios" $(6 \mathrm{M} 3,11)$. Así expresa la necesidad de confrontar el propio parecer con el de otros. En definitiva se trata de la necesidad de salir de uno mismo y confrontar la propia

11 Álvarez, Comentarios a 'Vida', 'Camino' y 'Moradas' de Santa Teresa.

12 Una panorámica sobre las personas con las que trató en Joseph Perez, Teresa de Ávila y la España de su tiempo (Madrid: Algaba, 2007), 151-190. 
visión con la de otro y que este otro sea realmente otro y no mi alter ego. Lo que da seguridad a la propia interioridad es esta referencia exterior a otros: "la seguridad que podemos tener es la obediencia y no torcer la ley de Dios" $(5 \mathrm{M} 3,2)$.

Otra exterioridad que tiene muy en cuenta es la que resulta de los efectos de las actitudes o acciones. La Palabra de Dios es siempre transformadora. Es el criterio evangélico: por sus frutos los conoceréis. La interioridad exige exteriorizarse para realizarse, para ser lo que es; estas exteriorizaciones son su verificación, criterios de verdad. Si ello es válido para toda interioridad, más aun en el caso del cristiano que por definición, siguiendo a su Maestro, es un ser para los demás.

El amor al prójimo es una salida de sí, de modo que es un remedio para las que están "encapotadas" $(5 \mathrm{M} 3,11)$ en su interioridad y oración. Y es que el amor al prójimo lleva consigo la necesidad de obrar. En ello la Santa se muestra muy decidida y taxativa: "que no, hermanas, no; obras quiere el Señor, y que, si ves una enferma a quien puedes dar algún alivio, no se te dé nada de perder esa devoción y te compadezcas de ella" $(5 \mathrm{M} 3,11)$.

\section{TRANSFORMACIÓN. PLENITUD Y DISOLUCIÓN DEL YO}

El itinerario que supone el recorrido de las moradas hasta su centro, es un proceso de transformación del alma, del yo, que va desde su apertura al Tú trascendente, a Dios, hasta su unión con Él. Los primeros cambios se manifiestan en que el sujeto cambia sus gustos y deseos, en un proceso de desprendimiento de sí mismo y de apertura y disposición a la voluntad de Dios.

Uno de los primeros efectos que observa la Santa es la "dilatación del corazón", tomando esta expresión bíblica del Salmo 118,32 (4M1,5). Es la experiencia de unos sentimientos, emociones, afectos interiores, que brotan de las capas más profundas del alma. Ya se sabe que en Teresa, como en toda la tradición cristiana y bíblica, el corazón designa el centro de la persona, de sus pensamientos y deseos, deliberaciones y decisiones, afectos y sentimientos, el yo más profundo, la interioridad. Esta dilatación tanto puede entenderse como una mayor apertura para el encuentro con Dios y recibir sus dones, como también como una mayor concentración en sí mismo, un fortalecimiento del sí mismo, en cuanto el corazón se ve liberado para desplegarse mejor en lo que le es más propio: amar. 
Esta dilatación puede verse tanto como un movimiento propio del alma, como también como una acción y gracia de Dios; ambas acciones van al unísono. Así lo explica la Santa: "no me parece que es cosa [...] que su nacimiento es del corazón, sino de otra parte aún más interior, como una cosa profunda. Pienso que debe ser el centro del alma" (4M2,5). Ahí tenemos afirmada una alteridad que es más íntima, más interior que el mismo corazón; "el centro del alma" es otro respecto de uno mismo, de modo que actúa desde el interior de uno mismo $\mathrm{y}$ en tanto que su propio interior. Por ser esta alteridad tan interiorizada, resulta que su acción es tanto de Dios como del alma. Los efectos transformadores del sujeto se exponen en $4 \mathrm{M} 3$, donde muestra que la oración no es un gesto aislado, sino va cambiando y configurando la vida del orante, de modo que sus "dejos" o efectos desbordan sobre la vida entera.

A partir de estos cambios en las actitudes se llega a una transformación de su propio ser, que Teresa explica con la metáfora de la transformación del gusano de seda en mariposa $(5 \mathrm{M} 2,2)^{13}$. Esta metáfora explica la unión por una metamorfosis del hombre que hace que le nazcan alas ("hanle nacido alas", $5 \mathrm{M} 2,8)$, que pueda volar, llevar otra vida, en definitiva, una vida más acercada a Dios. La Santa usa otras metáforas. Una es la de la abeja y la miel, la cual resalta la aportación del hombre; la abeja es la humildad, "que siempre labra". Otra metáfora es el sello y la cera; el sello es la marca de pertenencia $(5 \mathrm{M} 2,12)$. Una cuarta imagen del interior es la bodega $(5 \mathrm{M} 2,12)$, recordando la imagen del Cantar de los Cantares $(2,4)$, que sirve para indicar que se entra en los dominios del amor.

Mencionadas las metáforas más importantes, miremos qué se entiende por unión. El punto de partida es la convicción de que Dios está "en todas las cosas por presencia y potencia y esencia" $(5 \mathrm{M} 1,10)$, es decir la omnipresencia de Dios, por ello el hombre es "morada" de Dios, "posada", donde Él mora (Vida 1,8) ${ }^{14}$. Sin embargo, con frecuencia no tenemos consciencia de esta presencia. La toma de consciencia es obra de su amor y de su gracia. Acerca de qué entiende por unión afirma Teresa: "Sobre darme a entender qué es unión: «No pienses, hija, que es unión estar muy junta conmigo, porque también lo están los que me ofenden, aunque no quieren [...]». [...] Tornando a la unión, entendí que era este espíritu limpio y levantado de todas las cosas de la tierra, no quedar cosa de él

13 Santiago Guerra Sancho, "El gusano de seda y la mariposa. Una consideración históricoespiritual", en Las moradas del Castillo Interior de Santa Teresa de Jesús: Actas del IV Congreso Internacional Teresiano en preparación del V Centenario de su nacimiento (1515-2015), eds. Fermín Sancho Fermín y Rómulo H. Cuartas Londoño (Burgos: Monte Carmelo - Universidad de la Mística CITeS, 2014), 371-399.

14 Álvarez, Comentarios a 'Vida', 'Camino' y 'Moradas' de Santa Teresa, 625-627. 
que quiera salir de la voluntad de Dios, sino que de tal manera esté un espíritu $\mathrm{y}$ una voluntad conforme con la suya, y un desasimiento de todo, empleado en Dios, que no haya memoria de amor en sí ni en ninguna cosa criada. [...] Y paréceme a mí que si ésta es unión, estar tan hecha una nuestra voluntad y espíritu con el de Dios, que no es posible tenerla quien no esté en estado de gracia." (CC 26,1-4). En definitiva la unión no consiste en el simple estar junto, sino en el desprendimiento de sí y la entrega total de sí a Dios; en un desplazamiento de las funciones y de todo el dinamismo del espíritu: sentir, entender, amar, vivir en el propio cuerpo, todo ello queda transportado a otro plano en el que es posible la irrupción de lo divino; es una cierta experiencia de muerte y de vida, de resurrección. Se llega a la unión cuando desde lo hondo de la voluntad se conforma con la voluntad de Dios, se entra en empatía real con la voluntad de salvación de Dios; esta conformidad se convierte en el propio querer, de modo que ya no hay dos voluntades que tienen que acordarse, sino una sola, por la total adhesión de la humana a la divina, llegando a configurar la propia sensibilidad y afectividad, los criterios y los deseos. El amor, por ser unitivo, no tiene como término solamente a Dios, sino también a los hermanos. "Esta es la unión que toda mi vida he deseado; ésta es la que pido siempre a nuestro Señor y la que está más clara y segura" $(5 \mathrm{M} 3,5)^{15}$.

Finalmente, la gran metáfora y la mayor realización de la unión, que es a la vez la mayor experiencia y formación del sí mismo y a la vez su curso hacia una cierta disolución de sí: los desposorios (5M4) ${ }^{16}$ y el matrimonio espiritual (7M1).

El alma en su itinerario llega a su plenitud en las séptimas moradas, en el hondón interior, donde está Dios y "adonde pasan las cosas de mucho secreto entre Dios y el alma" (1M1,3), donde lo divino se hace presente y operante desde ese "hondón" del espíritu creado. Es el matrimonio espiritual (7M1,3). Esta nueva relación no es pasajera, "porque nunca más le parece se fueron [las tres divinas personas] de con ella [el alma], sino que notoriamente ve [...] que están en lo interior de su alma, en lo muy muy interior, en una cosa muy honda, que no sabe decir cómo es, $[\ldots]$ siente en sí esta divina compañía" $(7 \mathrm{M} 1,8)$. Esta compañía confiere un dinamismo en el hacer y el servir: "Pareceros ha que, según esto, no andará en sí, sino tan embebida que no pueda entender en nada. Mucho más que antes, en todo lo que es servicio de Dios" (7M1,9).

Además de esta relación especial con el Dios Trinidad, se da a la vez una especial identificación con Cristo y en concreto en su Humanidad. Esta nueva

15 Álvarez, Comentarios a 'Vida', 'Camino' y 'Moradas' de Santa Teresa, 639s.

16 Álvarez, Comentarios a 'Vida', 'Camino' y 'Moradas' de Santa Teresa, 643-650. 
relación con Cristo no es meramente de seguimiento o imitación, sino de compenetración de las dos vidas, de manera que puede decir con S. Pablo "mi vida es Cristo" (Gal 2,20). Así describe la Santa esta experiencia: "Viénenme días que me acuerdo infinitas veces de lo que dice San Pablo [...] que ni me parece vivo yo, ni hablo, ni tengo querer, sino que está en mí quien me gobierna y da fuerza, y ando como casi fuera de mí" (CC 3,10). Esta experiencia la glosará en su primer poema: "Vivo sin vivir en mí / [...]. Vivo ya fuera de mí / [...], porque vivo en el Señor" (p. 654). Se trata, pues, de la unión consumada de dos vidas. Ha sido tal la plenitud que una desaparece o se funde en el otro. También para explicar esta unión, Teresa recurrirá a imágenes: dos velas unidas que dan una sola luz; la unión del agua de lluvia que cae en el río, o el agua de un arroyo que entra en el mar (7M2,6). Ello no significa una simple fusión, puesto que "aunque la unión es juntarse dos cosas en una, en fin, se pueden separar y quedar cada cosa por sí" (7M2,5).

La Santa cuida de decirnos que el misterio de su relación con Cristo -su unión con él- es absolutamente interior: "unión de puro espíritu [...] con el Espíritu increado" (7M2,7). Esta presencia de la Humanidad de Cristo en ella es el término de un proceso que la Santa misma ha documentado. Así en Vida (cap. 27-28) ya insistió en la experiencia de tener a Jesús "cabe ella", "al lado", en todo caso frente a sí. Ahora en el estadio final, ese Jesús se le ha interiorizado. Se le ha instalado en el centro de su espíritu y de su vida. Aunque también esto es obra del Señor "en metiendo el Señor a el alma en esta morada suya, que es el centro de la mesma alma" (7M2,10).

\section{CONCLUSIÓN}

Las Moradas ofrecen un itinerario espiritual. ${ }^{17} \mathrm{El}$ inicio del itinerario de la relación entre el hombre y Dios viene dado por una subjetividad, consciente de sí misma, que está en sí, cabe sí. Para que se entable la relación ha de haber sujeto capaz de trabarla. Debe haber sujeto centrado en sí y no disperso al azar de los vientos de las opiniones o de los gustos. El sujeto, con esta predisposición, es el presupuesto para la relación, un alma en lucha por conseguir la paz interior y hacerse "más señora de sí".

17 En ello insisten un buen grupo de las contribuciones en (Sancho Fermín y Cuartas Londoño 2014), como Antonio Mas Arrondo, Secundino Castro Sánchez, Rómulo h. Cuartas Londoño, Fco. Javier Sancho Fermín, Teresa Gil. 
El alma es el lugar de encuentro entre Dios y el hombre, un encuentro algo peculiar, porque uno y otro no se perciben como externos uno al otro. El hombre, creado a imagen de Dios, partía ya de una gran afinidad y capacidad para el encuentro con Dios. Dios, por su parte, tiene en el alma su lugar propio, en lo más hondo de ella. Esta presencia del uno al otro tiene que penetrar en la propia conciencia, siendo para ello imprescindible un mayor autoconocimiento que sólo se consigue con el respectivo conocimiento de Dios.

En este proceso, hecho todo él de relaciones con otros y especialmente con el Otro, la Alteridad más íntima que uno mismo, tiene un momento de inflexión, el golpe de gracia a todo prometeísmo, la experiencia radical de la propia finitud, para renacer en una vida nueva, en una relación nueva con Dios y los demás que se irá profundizando hasta llegar a un desvivirse de sí mismo y viviendo el otro en mí y el yo en el otro. El resultado es que el otro no solo está dentro de mí como lo más íntimo del sí mismo, sino que el sí mismo en cierta manera desparece, se funde con el otro, se pasa a ser uno mismo en el otro, forma parte del sí mismo y el sí mismo del otro. La fusión tiene que matizarse en el sentido que, a pesar de la unión, se mantiene la diferencia, se trata de dos seres separables, pero unidos formando una sola identidad. La alteridad se ha convertido en la propia ipseidad y esta se ha alterado uniéndose a la Alteridad. "El sí mismo, como lugar del otro ${ }^{18 *}$.

\section{REFERENCIAS BIBLIOGRÁFICAS}

Álvarez, Tomás. Comentarios a 'Vida', 'Camino' y 'Moradas' de Santa Teresa. Burgos: Monte Carmelo, 2005.

Amengual, Gabriel. "La experiencia en el Libro de la Vida. Una lectura en clave filosófico-teológica". En Gabriel Amengual. Afines por elección. En torno a los inicios de la modernidad en España, 71-102. Madrid: Sindéresis, 2018. Amengual, Gabriel. "Interioridad y modernidad. La exploración de los espacios del alma en Santa Teresa de Jesús". En Gabriel Amengual. Afines por elección. En torno a los inicios de la modernidad en España, 103-114. Madrid: Sindéresis, 2018.

Amengual, Gabriel. "La concepción ignaciana del sujeto". Argumenta Philosophica (2021), en prensa.

18 Michel de Certeau, "La ficción del alma, fundamento de las 'Moradas'“. In Id., La Fábula mistica. (Siglos XVI-XVII). Madrid: Siruela, 2006, 196. 
Amengual, Gabriel. "P. Ricoeur: Del sujeto quebrado a la hermenéutica del sí". Anthologica Annua (2021), en prensa.

Andrés Martín, Melquíades. "Procesos de interioridad en la mística española (1500-1535). La reflexión de las potencias al centro del alma, como método dialéctico para la contemplación quieta". En Santa Teresa y la literatura mística hispánica, dirigida por Criado de Val, Manuel, 7-23. Madrid: Edi-6, 1984.

Astigarraga, Juan Luís y Agustí Borrell, eds. Concordancias de los escritos de Santa Teresa de Jesús. Roma: OCD, 2002, 2 vols.

Certeau, Michel de. "La ficción del alma, fundamento de las 'Moradas'". En Michel de Certeau, La Fábula mística. (Siglos XVI-XVII), 187-199. Madrid: Siruela, 2006.

Guerra Sancho, Santiago. "El gusano de seda y la mariposa. Una consideración histórico-espiritual". En Las moradas del Castillo Interior de Santa Teresa de Jesús: Actas del IV Congreso Internacional Teresiano en preparación del V Centenario de su nacimiento (1515-2015), editado por Fermín Sancho y Rómulo H. Cuartas Londoño, 371-399. Burgos: Monte Carmelo - Universidad de la Mística-CITES, 2014.

Pérez, Joseph. Teresa de Ávila y la España de su tiempo. Madrid: Algaba, 2007.

Ricoeur, Paul. Soi-même comme un autre. Paris: Seuil, 1990.

Sancho Fermín, Francisco Javier y Rómulo H. Cuartas Londoño, eds. Las Moradas del Castillo Interior de Santa Teresa de Jesús. Burgos: Monte Carmelo - Universidad de la Mística-CITES, 2014.

Teresa de Jesús, Santa. Obras completas. Ed. de Efrén de la Madre de Dios y Otger Steggink, 9a ed. Madrid: BAC, 2002.

Gabriel Amengual Coll Instituto de Estudios Hispánicos en la Modernidad (IEHM) Universitat de les Illes Balears Edificio Ramon Llull, Cra. de Valldemossa, km. 7.5 07122 Palma de Mallorca (España) https://orcid.org//0000-0001-7367-3888 
